\title{
Pancreatic Neuroendocrine Tumor pM1 TNM Finding v8
}

National Cancer Institute

\section{Source}

National Cancer Institute. Pancreatic Neuroendocrine Tumor pM1 TNM Finding v8. NCI Thesaurus. Code C135546.

Pancreatic neuroendocrine tumor with distant metastasis. (from AJCC 8th Ed.) 